\title{
Antirheumatic Drug Intake Influence on Occurrence of COVID-19 Infection in Ambulatory Patients with Immune-Mediated Inflammatory Diseases: A Cohort Study
}

Debellemanière Guillaume $\cdot$ Bouvet Magalie $\cdot$ Elahi Sina $\cdot$ Salah-Mabed Imène $\cdot$ Vayr Frédéric $\cdot$ Dubois Mathieu $\cdot$ Muselier Aurore · Gozlan Yoni · Elbaz Emma · Badatcheff Charlotte · Fabre Laura · Saad Alain · Nahaisi Steven • Zeboulon Pierre $\cdot$ Febbraro Jean-Luc $\cdot$ Courtin Romain · Grise-Dulac Alice • Mazharian Adrien • Ghazal Wassim • Remongin Pierre-Emmanuel · Panthier Christophe · Chirouze Catherine · Bertrand Kevin · Sené Thomas • Gatinel Damien

Received: July 14, 2020 / Accepted: September 6, 2021 / Published online: September 16, 2021

(C) The Author(s) 2021

\section{ABSTRACT}

Introduction: We aimed to study the prevalence of a history of COVID-19 infection among patients suffering from systemic lupus erythematosus (SLE), rheumatoid arthritis (RA), Sjögren's syndrome (SjS) or psoriatic arthritis (PsA), and the potential influence of long-term hydroxychloroquine (HCQ) intake.

Methods: We performed an observational monocentric cohort study at the Adolphe de Rothschild Foundation Hospital ophthalmology division (Paris, France). Electronic medical records (EMR) data were searched for keywords associated with SLE, RA, SjS, or PsA. Patients

Bertrand Kevin and Sené Thomas contributed equally to this work.

D. Guillaume · B. Magalie · E. Sina · S.-M. Imène

V. Frédéric · D. Mathieu - M. Aurore · G. Yoni

E. Emma - B. Charlotte - F. Laura - S. Alain ·

N. Steven · Z. Pierre - F. Jean-Luc $\cdot$ C. Romain .

G.-D. Alice · M. Adrien · G. Wassim •

R. Pierre-Emmanuel · P. Christophe $\cdot$ S. Thomas .

G. Damien $(\square)$

Adolphe de Rothschild Foundation Hospital, 29 Rue

Manin, Paris, France

e-mail: gatinel@gmail.com

C. Catherine

Jean Minjoz University Hospital, Besançon, France

B. Kevin

Perpignan Hospital, Perpignan, France were contacted by phone and were interviewed using a standardized questionnaire. The primary outcome was the occurrence of a positive COVID-19 test result during the study period. We determined the adjusted association between various antirheumatic drugs intake, COVID-19 risk factors, and occurrence of COVID-19 using a logistic regression model. This study is registered on ClinicalTrials.gov (Identifier: NCT04345159).

Results: Patients were recruited between Apr 17, 2020, and Apr 30, 2020 and were recontacted between Oct 6, 2020, and Nov 2, 2020. A total of 569 patients were included, of whom 459 patients were eligible for data analysis. One hundred and eighty-one patients were treated with long-term HCQ and 18 patients had tested positive for COVID-19. No antirheumatic drug intake, including HCQ intake, was significantly associated with an increased or decreased risk of developing COVID-19 infection.

Conclusions: No antirheumatic drug intake was associated with an increased or decreased risk of developing COVID-19 infection in our cohort of patients suffering from immune-mediated inflammatory diseases.

Keywords: Systemic lupus erythematosus; Rheumatoid arthritis; Sjögren's syndrome; Psoriatic arthritis; Hydroxychloroquine; Antirheumatic drugs 


\section{Key Summary Points}

Why carry out this study?

The role of antirheumatic drugs, including hydroxychloroquine, as a risk factor or protective factor in COVID-19 infection has been debated.

These drugs are predominantly used to treat patients with immune-mediated inflammatory diseases.

We wanted to determine the influence of antirheumatic drugs on the incidence of COVID-19 infection in a cohort of patients suffering from immune-mediated inflammatory diseases.

\section{What was learned from this study?}

No major prophylactic effect of long-term HCQ intake was observed in our cohort.

Patients with immune-mediated inflammatory diseases taking HCQ can be infected with SARS-CoV-2 and develop severe forms of COVID-19 infection.

\section{INTRODUCTION}

The potential role of hydroxychloroquine (HCQ) in the coronavirus disease 2019 (COVID19) pandemic caused by the coronavirus strain SARS-CoV-2 has been debated. An in vitro effect of hydroxychloroquine against SARS-CoV-2 has been described $[1,2]$.

Early reports have suggested that hydroxychloroquine and azithromycin association allowed respiratory viral load reduction [3]. The same team reported a clinical benefit of this association in a retrospective study [4]. Lower incidences of SARS-CoV-2 infections were noted among patients suffering from rheumatic diseases under treatment with hydroxychloroquine [5]. Hydroxychloroquine oral chemoprophylaxis has been described as effective in young and healthy men in a randomized trial [6]. Conversely, hydroxychloroquine intake with or without azithromycin has been found to be ineffective against COVID-19 infection in multiple observational [7-14], intent-to-treat [15], and randomized controlled [16-24] studies. Recently published meta-analysis found that hydroxychloroquine had no efficacy as a prophylaxis for COVID-19 infections [25], and no clinical benefit in patients hospitalized for COVID-19 [26-30].

We aimed to study the potential influence of long-term HCQ intake on the prevalence of a history of COVID-19 infection among patients having an ophthalmological follow-up in our center and suffering from systemic lupus erythematosus (SLE), rheumatoid arthritis (RA), Sjögren's syndrome (SjS), or psoriatic arthritis (PsA).

\section{METHODS}

\section{Study Design and Participants}

In this transversal, monocenter, observational cohort study, we aimed to determine the association of ongoing long-term HCQ treatment with the incidence of confirmed COVID-19 infection in patients with SLE, RA, SjS, and/or PsA followed at the Adolphe de Rothschild Foundation Hospital, which is a center dedicated to the treatment of eye and brain diseases. Data were collected from Adolphe de Rothschild Foundation Hospital's data warehouse. EMR containing keywords relevant with a history of SLE, RA, SjS, PsA, or a history of HCQ intake were extracted. All potentially relevant patients were called by phone between April 17, 2020 and April 30, 2020. After having obtained informed consent of the patient, the interview was conducted using a standardized questionnaire about their medical history and their regimen. A second call was made 5 months later. Exclusion criteria were: patient's refusal to participate in the study; no history of corresponding pathology; poor compliance with hydroxychloroquine treatment reported by the patient; introduction, modification, or interruption of hydroxychloroquine treatment between Jan 1, 2020 and Nov 2, 2020. Primary outcome was a history of COVID-19 infection confirmed by serology, PCR, or antigen 
test. Each patient was given detailed oral information and the rationale for the study was explained. Oral consent was then collected and consigned. This proceeding was followed by written information sent by e-mail or by post. The COVCALL protocol was approved by research ethics committees Nord-Ouest 1 in France. The "Centre d'investigation clinique" of Rothschild foundation gave approval to access the data. The study was performed in accordance with the declaration of Helsinki 1964 and its later amendments.

\section{Procedures}

A group of ophthalmologists was responsible for calling the patients between April 17, 2020 and April 30, 2020. The survey looked for a history of SLE, RA, SjS, PsA; other relevant medical conditions; posology, duration, and observance of a current or past HCQ treatment; other relevant treatments; stability of the pathology under treatment; blood type of the patient; non-steroidal anti-inflammatory (NSAID), corticosteroid, immunosuppressant, conventional or biological disease modifying antirheumatic drugs (cDMARDs, bDMARDs) drug intake; results of COVID-19 real-time reverse transcription polymerase chain reaction (rRT-PCR) testing if it had been performed; history of COVID-19 infection assessed by a doctor; occurrence and cause of a recent hospitalization; symptoms compatible with a COVID-19 infection. Low-dose aspirin prophylaxis was not considered as NSAID intake. The questionnaire used for the interview was standardized and clear instructions were given to the investigators. Patients were called back between Oct 6, 2020, and Nov 2, 2020: they were asked if a COVID-19 test had been realized in the meanwhile, its outcome if appropriate, initiation or termination of HCQ intake between the inclusion and the test, and occurrence of COVID-19related hospitalization.

\section{Outcomes}

The primary endpoint was the occurrence of a biologically confirmed COVID-19 infection.

\section{Statistical Analysis}

Python 3.7.5, Scikit learn 0.21.3, Pandas 0.25.3, and Statsmodels 0.11 .1 were used for data handling and statistical analysis. We used a logistic regression model to quantify the association between group characteristics and primary outcome. Confirmed COVID-19 infection was the dependent variable of the model. Age, as a continuous feature, was standardized by scaling the maximum value to unit size and the minimum value to 0 using Scikit learn MinMaxScaler function. Other categorical variables had only two possible values. Because of the low number of proven COVID-19 infections, COVID-19 comorbidities were analyzed as a whole. Because of missing data, blood type was not included in the analysis. In order to handle multicollinearity among features, variation inflation factors (VIF) were calculated using statsmodels variance_inflation_factor function. A maximum VIF value of 5 was considered acceptable. A logistic regression model (implemented in Python statsmodels 0.11.1 library using the logit function with L1 regularization) was trained to predict the dependent variable. Non-informative variables were then dropped and the model was refitted. Odds ratios associated with each feature were obtained by calculating the exponential function of each coefficient value and related $p$ value was reported.

\section{RESULTS}

A total of 2027 patients with relevant keywords in their EMR were found in the Rothschild Foundation Hospital data warehouse. A first screening aimed at removing the EMR mentioning a disease in another context than mentioning it as a diagnosis was performed; 1889 EMR were assessed for eligibility in this study and called between Apr 17, 2020 and Apr 30, 2020. Nine hundred and sixty-three patients $(51.0 \%)$ could not be reached by phone. Among the 926 patients reached by phone, 155 (16.7\%) declined to participate or were not able to answer, and 202 patients (21.8\%) did not meet the inclusion criteria (none of the four 
Table 1 Demographic data of study participants

\begin{tabular}{|c|c|c|}
\hline & No HCQ intake $(n=278)$ & HCQ intake $(n=181)$ \\
\hline Patient age (years) & $61.5(14.1 ; 21.0-97.0)$ & $56.1(15.0 ; 22.0-93.0)$ \\
\hline Female & $n=245(88.1 \%)$ & $n=171(94.5 \%)$ \\
\hline Duration of HCQ treatment & - & $10.9(8.8 ; 0.5-40.0)$ \\
\hline SLE & $n=83(29.9 \%)$ & $n=110(60.8 \%)$ \\
\hline SjS & $n=114(41.0 \%)$ & $n=50(27.6 \%)$ \\
\hline RA & $n=94(33.8 \%)$ & $n=55(30.4 \%)$ \\
\hline PsA & $n=40(14.4 \%)$ & $n=3(1.7 \%)$ \\
\hline Chronic bronchitis & $n=23(8.3 \%)$ & $n=10(5.5 \%)$ \\
\hline Cancer & $n=22(7.9 \%)$ & $n=17(9.4 \%)$ \\
\hline CVD & $n=101(36.3 \%)$ & $n=66(36.5 \%)$ \\
\hline Diabetes & $n=20(7.2 \%)$ & $n=13(7.2 \%)$ \\
\hline Comorbidities (all) & $n=130(46.8 \%)$ & $n=87(48.1 \%)$ \\
\hline NSAIDs & $n=43(15.5 \%)$ & $n=19(10.5 \%)$ \\
\hline Corticosteroids & $n=163(58.6 \%)$ & $n=105(58.0 \%)$ \\
\hline IS & $n=6(2.2 \%)$ & $n=6(3.3 \%)$ \\
\hline cDMARDS & $n=51(18.3 \%)$ & $n=17(9.4 \%)$ \\
\hline bDMARDS & $n=17(6.1 \%)$ & $n=3(1.7 \%)$ \\
\hline JAKi & $n=7(2.5 \%)$ & $n=1(0.6 \%)$ \\
\hline Tested & $n=130(46.8 \%)$ & $n=95(52.5 \%)$ \\
\hline Tested positive & $n=12(4.3 \%)$ & $n=6(3.3 \%)$ \\
\hline Hospitalization related to COVID-19 infection & $n=3(1.1 \%)$ & $n=2(1.1 \%)$ \\
\hline
\end{tabular}

$C V D$ cardiovascular diseases, $D V T-P E$ deep vein embolism/pulmonary embolism

pathologies necessary to be included, modification of hydroxychloroquine treatment between Jan 1, 2020 and time of survey and/or bad hydroxychloroquine treatment compliance), leaving 569 patients. After the second call, 16 patients were excluded from the analysis for the same reasons, 13 declined to answer, and 81 were lost to follow-up, leaving 459 patients suitable for analysis. Among those 459 patients, 225 had benefited from a COVID-19 test, of which 18 were positive.

Demographics of the population is presented in Table 1. The main pathology leading to inclusion was SLE $(n=193)$, followed by $\mathrm{SjS}$ $(n=164)$. Some patients $(n=84)$ cumulated different pathologies. The most represented comorbidity was a history of cardiovascular disease $(n=167) ; 120$ patients $(26.1 \%)$ did not know their blood type: therefore, this variable was excluded from the analysis; 181 patients were on long-term HCQ treatment. Among them, six (3.3\%) described COVID-19-compatible symptoms during the epidemic period. This proportion was similar among the non-HCQ group $(n=12,4.3 \%)$. Among the patients who tested positive for COVID-19 infection, five were hospitalized: two of them were under long-term HCQ treatment. 
Table 2 Odds ratio, confidence intervals, and associated $p$ values of studied parameters

\begin{tabular}{llrrr}
\hline & $\begin{array}{l}\text { Odds } \\
\text { ratio }\end{array}$ & $\mathbf{2 . 5 \%}$ & $\mathbf{9 7 . 5 \%}$ & $\boldsymbol{p}$ value \\
\hline Female & 0.77 & 0.16 & 3.66 & 0.747 \\
Patient age & 0.72 & 0.03 & 14.94 & 0.829 \\
SLE & 0.62 & 0.15 & 2.63 & 0.521 \\
SjS & 1.2 & 0.34 & 4.27 & 0.775 \\
RA & 1.34 & 0.35 & 5.16 & 0.671 \\
PsA & 0.52 & 0.05 & 5.58 & 0.592 \\
Disease stability & 0.46 & 0.15 & 1.46 & 0.188 \\
NSAIDs & 0.73 & 0.15 & 3.53 & 0.695 \\
Corticosteroids & 1.41 & 0.5 & 3.95 & 0.516 \\
cDMARDS & 1.48 & 0.42 & 5.29 & 0.544 \\
bDMARDS & 1.17 & 0.13 & 10.79 & 0.889 \\
Comorbidities (all) & 1.39 & 0.47 & 4.07 & 0.554 \\
Active HCQ & 1.03 & 0.33 & 3.2 & 0.955 \\
treatment & & & & \\
\hline
\end{tabular}

The maximum VIF value was 2.21 and therefore no variables were dropped because of multicollinearity. L1 regularization led to drop the "Immunosuppressant intake" and "JAKi intake" features. Mean value or percentages, odds ratio, and $p$ value of each selected feature are presented in Table 2. No feature, including HCQ intake, was significantly associated with a lower risk of COVID-19 infection. The lowest $p$ value $(0.188)$ was associated with the "Disease stability" feature, which had an OR of 0.46, suggesting a possible greater risk of COVID-19 infection in patients with a non-stabilized disease.

\section{DISCUSSION}

Because of their exposure to HCQ before the outbreak, the population of patients under long-term HCQ medication is of particular interest. A study evaluating a cohort of 165 patients with SLE using telemedicine found no evidence of protective action of HCQ and confirmed the occurrence of COVID-19 infection in patients taking HCQ. No COVID-19 infection risk reduction was found in an observational study analyzing 800 patients under long-term HCQ treatment and 449 controls [31]. Long-term HCQ intake was not associated with less severe presentations of COVID-19 among 14 hospitalized patients suffering from rheumatic conditions, matched with 28 control subjects [8]. In an observational study including 47 patients with rheumatic diseases who tested positive on a COVID-19 PCR, $25.5 \%$ of the patients were under long-term HCQ treatment and HCQ intake had no significant influence on the occurrence of severe COVID-19 pneumonia [32]. No reduction in COVID-19 mortality was found in a cohort of 194,637 patients with RA or SLE, of which 30,569 were taking HCQ and 547 died from COVID-19 infection [12], and no significant hospitalization rate reduction was found in a cohort of 58,052 patients with inflammatory rheumatic disease, of which 2722 were treated with HCQ [33].

A series of 17 patients with SLE treated with long-term HCQ and having developed severe forms of COVID-19 has been published [8].

Our study has some inherent limitations. Firstly, only 18 patients tested positive, and no variable reached statistical significance. Patients were interviewed by phone without physical examination and may consequently have given incomplete or wrong answers. Notably, $26 \%$ of the patients were unaware of their blood type. Another limitation of this study is the possibility that some patients did not answer the phone because of a more severe COVID-19 presentation leading to hospitalization or death, or on the contrary were infected but asymptomatic. In addition, our cohort was constituted of patients having an ophthalmologic follow-up, and may not be representative of patients with immune-mediated inflammatory diseases as a whole. The patient's ethnicity and social characteristics data were not collected in our study for regulatory reasons. This may also act as a confounding factor, as suggested by recent reports [34-38].

Despite its inherent shortcomings, this study brings interesting data. No major prophylactic effect of long-term HCQ intake was observed in 
our cohort. Our study provides information confirming the fact that patients with immunemediated inflammatory diseases taking HCQ can be infected with SARS-CoV-2 and develop severe forms of COVID-19 infection.

\section{CONCLUSIONS}

Our work does not support any prophylactic effect of long-term HCQ intake in COVID-19 infection in our population of patients suffering from immune-mediated inflammatory diseases and having an ophthalmological follow-up.

\section{ACKNOWLEDGEMENTS}

Funding. No funding or sponsorship was received for this study or publication of this article. The Rapid Service Fee was funded by the research association of the Rothschild Foundation anterior segment surgery department (CEROC).

Authorship. All named authors meet the International Committee of Medical Journal Editors (ICMJE) criteria for authorship for this article, take responsibility for the integrity of the work as a whole, and have given their approval for this version to be published.

Author Contributions. Study conception and design: Debellemanière G, Gatinel D. Data analysis: Debellemanière G. Data collection: Badatcheff C, Bertrand K, Bouvet M, Chirouze C, Courtin R, Debellemanière $G$, Dubois $M$, Elahi S, Elbaz E, Fabre L, Febbraro JL, Gatinel D, Ghazal W, Gozlan Y, Grise-Dulac A, Mazharian A, Muselier A, Nahaisi S, Panthier C, Remongin PE, Saad A, Salah-Mabed I, Sené T, Vayr F, Zeboulon P. Draft manuscript preparation: Debellemanière G, Gatinel D.

Disclosures. Dr. Thomas Sené reports nonfinancial support from Sanofi-Aventis, non-financial support from Shire, outside the submitted work; Dr. Kevin Bertrand reports nonfinancial support from Gilead, outside the submitted work. Debellemanière Guillaume, Bouvet Magalie, Elahi Sina, Salah-Mabed Imène, Vayr Frédéric, Dubois Mathieu, Muselier Aurore, Gozlan Yoni, Elbaz Emma, Badatcheff Charlotte, Fabre Laura, Saad Alain, Nahaisi Steven, Zeboulon Pierre, Febbraro Jean-Luc, Courtin Romain, Grise-Dulac Alice, Mazharian Adrien, Ghazal Wassim, Remongin Pierre-Emmanuel, Panthier Christophe, Chirouze Catherine, and Gatinel Damien have nothing to disclose.

Compliance with Ethics Guidelines. The COVCALL protocol was approved by research ethics committees Nord-Ouest 1 in France. The "Centre d'investigation clinique" of Rothschild Foundation gave approval to access the data. Each patient was given detailed oral information and the rationale for the study was explained. Oral consent was then collected and consigned. This proceeding was followed by written information sent by e-mail or by post. The study was conducted in accordance with the Declaration of Helsinki 1964 and its later amendments.

Data Availability. The datasets generated during and/or analyzed during the current study are available from the corresponding author on reasonable request.

Open Access. This article is licensed under a Creative Commons Attribution-NonCommercial 4.0 International License, which permits any non-commercial use, sharing, adaptation, distribution and reproduction in any medium or format, as long as you give appropriate credit to the original author(s) and the source, provide a link to the Creative Commons licence, and indicate if changes were made. The images or other third party material in this article are included in the article's Creative Commons licence, unless indicated otherwise in a credit line to the material. If material is not included in the article's Creative Commons licence and your intended use is not permitted by statutory regulation or exceeds the permitted use, you will need to obtain permission directly from the copyright holder. To view a copy of this licence, visit http://creativecommons.org/licenses/by$\mathrm{nc} / 4.0 /$. 


\section{REFERENCES}

1. Liu J, Cao R, Xu M, Wang X, Zhang H, Hu H, et al. Hydroxychloroquine, a less toxic derivative of chloroquine, is effective in inhibiting SARS-CoV-2 infection in vitro. Cell Discov. 2020;6(1):16.

2. Yao X, Ye F, Zhang M, Cui C, Huang B, Niu P, et al. In vitro antiviral activity and projection of optimized dosing design of hydroxychloroquine for the treatment of severe acute respiratory syndrome coronavirus 2 (SARS-CoV-2). Clin Infect Dis. 2020;71(15):732-9.

3. Gautret P, Lagier J-C, Parola P, Hoang VT, Meddeb $\mathrm{L}$, Mailhe $\mathrm{M}$, et al. Hydroxychloroquine and azithromycin as a treatment of COVID-19: results of an open-label non-randomized clinical trial. Int J Antimicrob Agents. 2020;56(1):105949.

4. Lagier J-C, Million M, Gautret $\mathrm{P}$, Colson $\mathrm{P}$, Cortaredona S, Giraud-Gatineau A, et al. Outcomes of 3,737 COVID-19 patients treated with hydroxychloroquine/azithromycin and other regimens in Marseille, France: a retrospective analysis. Travel Med Infect Dis. 2020;36:101791.

5. Ferreira A, Oliveira-E-Silva A, Bettencourt P. Chronic treatment with hydroxychloroquine and SARS-CoV-2 infection. J Med Virol. 2021;93(2): 755-9.

6. Seet RCS, Quek AML, Ooi DSQ, Sengupta S, Lakshminarasappa SR, Koo CY, et al. Positive impact of oral hydroxychloroquine and povidone-iodine throat spray for COVID-19 prophylaxis: an openlabel randomized trial. Int J Infect Dis. 2021;106: 314-22.

7. Rosenberg ES, Dufort EM, Udo T, Wilberschied LA, Kumar J, Tesoriero J, et al. Association of treatment with hydroxychloroquine or azithromycin with inhospital mortality in patients with COVID-19 in New York State. JAMA. 2020;323(24):2493-502.

8. Mathian A, Mahevas M, Rohmer J, Roumier M, Cohen-Aubart F, Amador-Borrero B, et al. Clinical course of coronavirus disease 2019 (COVID-19) in a series of 17 patients with systemic lupus erythematosus under long-term treatment with hydroxychloroquine. Ann Rheum Dis. 2020;79(6):837-9.

9. Konig MF, Kim AHJ, Scheetz MH, Graef ER, Liew JW, Simard J, et al. Baseline use of hydroxychloroquine in systemic lupus erythematosus does not preclude SARS-CoV-2 infection and severe COVID19. Ann Rheum Dis. 2020;79(10):1386-8.

10. Sbidian E, Penso L, Herlemont P, Botton J, Baricault $B$, Semenzato L, et al. Comment on "Baseline use of hydroxychloroquine in systemic lupus erythematosus does not preclude SARS-CoV-2 infection and severe COVID-19" by Konig et al. Long-term exposure to hydroxychloroquine or chloroquine and the risk of hospitalisation with COVID-19: a nationwide, observational cohort study in 54,873 exposed individuals and 155,689 matched unexposed individuals in France. Ann Rheum Dis. 2020. https://doi.org/10.1136/ annrheumdis-2020-218647.

11. Gianfrancesco M, Hyrich KL, Al-Adely S, Carmona L, Danila MI, Gossec L, et al. Characteristics associated with hospitalisation for COVID-19 in people with rheumatic disease: data from the COVID-19 Global Rheumatology Alliance physician-reported registry. Ann Rheum Dis. 2020;79(7):859-66.

12. Rentsch CT, DeVito NJ, MacKenna B, Morton CE, Bhaskaran K, Brown JP, et al. Effect of pre-exposure use of hydroxychloroquine on COVID-19 mortality: a population-based cohort study in patients with rheumatoid arthritis or systemic lupus erythematosus using the OpenSAFELY platform. Lancet Rheumatol. 2021;3(1):e19-27.

13. Geleris J, Sun Y, Platt J, Zucker J, Baldwin M, Hripcsak G, et al. Observational study of hydroxychloroquine in hospitalized patients with Covid-19. N Engl J Med. 2020;382(25):2411-8.

14. Sammartino D, Jafri F, Cook B, La L, Kim H, Cardasis J, et al. Predictors for inpatient mortality during the first wave of the SARS-CoV-2 pandemic: a retrospective analysis. PLoS ONE. 2021;16(5): e0251262.

15. Gerlovin H, Posner DC, Ho Y-L, Rentsch CT, Tate JP, King JT Jr, et al. Pharmacoepidemiology, machine learning and COVID-19: an intent-to-treat analysis of hydroxychloroquine, with or without azithromycin, and COVID-19 outcomes amongst hospitalized US Veterans. Am J Epidemiol. 2021. https://doi.org/10.1093/aje/kwab183.

16. Cavalcanti AB, Zampieri FG, Rosa RG, Azevedo LCP, Veiga VC, Avezum A, et al. Hydroxychloroquine with or without azithromycin in mild-to-moderate Covid-19. N Engl J Med. 2020;383(21):2041-52.

17. Schwartz I, Boesen ME, Cerchiaro G, Doram C, Edwards BD, Ganesh A, et al. Assessing the efficacy and safety of hydroxychloroquine as outpatient treatment of COVID-19: a randomized controlled trial. CMAJ Open. 2021;9(2):E693-702.

18. Sivapalan P, Suppli Ulrik C, Sophie Lapperre T, Dahlin Bojesen R, Eklöf J, Browatzki A, et al. Azithromycin and hydroxychloroquine in hospitalised patients with confirmed COVID-19-a randomised double-blinded placebo-controlled trial. Eur Respir J. 2021. https://doi.org/10.1183/13993003.007522021. 
19. Ader F, Peiffer-Smadja N, Poissy J, BouscambertDuchamp M, Belhadi D, Diallo A, et al. An openlabel randomized controlled trial of the effect of lopinavir/ritonavir, lopinavir/ritonavir plus IFN- $\beta$ $1 \mathrm{a}$ and hydroxychloroquine in hospitalized patients with COVID-19. Clin Microbiol Infect. 2021. https://doi.org/10.1016/j.cmi.2021.05.020.

20. Réa-Neto Á, Bernardelli RS, Câmara BMD, Reese FB, Queiroga MVO, Oliveira MC. An open-label randomized controlled trial evaluating the efficacy of chloroquine/hydroxychloroquine in severe COVID19 patients. Sci Rep. 2021;11(1):9023.

21. Reis G, Moreira Silva EADS, Medeiros Silva DC, Thabane L, Singh G, Park JJH, et al. Effect of early treatment with hydroxychloroquine or lopinavir and ritonavir on risk of hospitalization among patients with COVID-19: the TOGETHER randomized clinical trial. JAMA Netw Open. 2021;4(4): e216468.

22. Dubée V, Roy P-M, Vielle B, Parot-Schinkel E, Blanchet O, Darsonval A, et al. Hydroxychloroquine in mild-to-moderate coronavirus disease 2019: a placebo-controlled double blind trial. Clin Microbiol Infect. 2019. https://doi.org/10.1016/j. cmi.2021.03.005.

23. Galan LEB, Santos NMD, Asato MS, Araújo JV, de Lima MA, Araújo AMM, et al. Phase 2 randomized study on chloroquine, hydroxychloroquine or ivermectin in hospitalized patients with severe manifestations of SARS-CoV-2 infection. Pathog Glob Health. 2021;115(4):235-42.

24. Johnston C, Brown ER, Stewart J, Karita HCS, Kissinger PJ, Dwyer J, et al. Hydroxychloroquine with or without azithromycin for treatment of early SARS-CoV-2 infection among high-risk outpatient adults: a randomized clinical trial. EClinicalMedicine. 2021;33:100773.

25. Hernandez AV, Ingemi J 3rd, Sherman M, Pasupuleti V, Barboza JJ, Piscoya A, et al. Impact of prophylactic hydroxychloroquine on people at high risk of COVID-19: a systematic review and metaanalysis. J Clin Med Res. 2021. https://doi.org/10. 3390/jcm10122609.

26. Hernandez AV, Phan MT, Rocco J, Pasupuleti V, Barboza JJ, Piscoya A, et al. Efficacy and safety of hydroxychloroquine for hospitalized COVID-19 patients: a systematic review and meta-analysis. J Clin Med Res. 2021. https://doi.org/10.3390/ jcm10112503.

27. Di Castelnuovo A, Costanzo S, Cassone A, Cauda R, De Gaetano G, Iacoviello L. Hydroxychloroquine and mortality in COVID-19 patients: a systematic review and a meta-analysis of observational studies and randomized controlled trials. Pathog Glob Health. 2021;15:1-11.

28. Amani B, Khanijahani A, Amani B. Hydroxychloroquine plus standard of care compared with standard of care alone in COVID-19: a meta-analysis of randomized controlled trials. Sci Rep. 2021;11(1):11974.

29. Axfors C, Schmitt AM, Janiaud P, Van't Hooft J, Abd-Elsalam S, Abdo EF, et al. Mortality outcomes with hydroxychloroquine and chloroquine in COVID-19 from an international collaborative meta-analysis of randomized trials. Nat Commun. 2021;12(1):2349.

30. Eze P, Mezue KN, Nduka CU, Obianyo I, Egbuche O. Efficacy and safety of chloroquine and hydroxychloroquine for treatment of COVID-19 patients-a systematic review and meta-analysis of randomized controlled trials. Am J Cardiovasc Dis. 2021;11(1): 93-107.

31. Yousefghahari B, Navari S, Sadeghi M, Soleimaniamiri S, Soleimaniamiri M, Heidari B, et al. Risk of COVID-19 infection in patients with rheumatic disease taking disease-modifying anti-rheumatic drugs. Clin Rheumatol. 2021. https://doi.org/10. 1007/s10067-021-05779-4.

32. Pham K, Torres H, Satlin MJ, Goyal P, Gulick RM. Failure of chronic hydroxychloroquine in preventing severe complications of COVID-19 in patients with rheumatic diseases. Rheumatol Adv Pract. 2021;5(1):rkab014.

33. Cordtz R, Lindhardsen J, Soussi BG, Vela J, Uhrenholt L, Westermann $\mathrm{R}$, et al. Incidence and severeness of COVID-19 hospitalisation in patients with inflammatory rheumatic disease: a nationwide cohort study from Denmark. Rheumatology. 2020. https://doi.org/10.1093/rheumatology/keaa897.

34. Dalton JE, Gunzler DD, Jain V, Perzynski AT, Dawson NV, Einstadter D, Tarabichi Y, Imrey PB, Lewis M, Kattan MW, Yao J, Taksler G, Berg KA, Krieger NI, Kaelber D, Jehi L, Kalra A. Mechanisms of socioeconomic differences in COVID-19 screening and hospitalizations. PLoS ONE. 2021;16(8): e0255343.

35. Zerbo O, Lewis N, Fireman B, Goddard K, Skarbinski J, Sejvar JJ, Azziz-Baumgartner E, Klein NP. Population-based assessment of risks for severe COVID19 disease outcomes. Influenza Other Respir Viruses. 2021.

36. Sandoval M, Nguyen DT, Vahidy FS, Graviss EA. Risk factors for severity of COVID-19 in hospital patients aged 18-29 years. PLoS ONE. 2021;16(7): e0255544. 
37. Zhang Y, Khullar D, Wang F, Steel P, Wu Y, Orlander D, Weiner M, Kaushal R. Socioeconomic variation in characteristics, outcomes, and healthcare utilization of COVID-19 patients in New York City. PLoS ONE. 2021;16(7):e0255171.

38. Lo CH, Nguyen LH, Drew DA, Warner ET, Joshi AD, Graham MS, Anyane-Yeboa A, Shebl FM, Astley CM, Figueiredo JC, Guo CG, Ma W, Mehta RS,
Kwon S, Song M, Davies R, Capdevila J, Sudre $\mathrm{CH}$, Wolf J, Cozier YC, Rosenberg L, Wilkens LR, Haiman CA, Marchand LL, Palmer JR, Spector TD, Ourselin S, Steves CJ, Chan AT, COPE Consortium. Race, ethnicity, community-level socioeconomic factors, and risk of COVID-19 in the United States and the United Kingdom. EClinical Medicine. 2021;38:101029. 